\title{
The preventive effect of DHL-HisZnNa, an $\alpha$-lipoic acid derivative, for chemotherapy-induced alopecia: a single-arm phase 3 study
}

Noriko Sagawa ${ }^{1)}$, Yohei Kono'), Shinji Ohno ${ }^{2)}$, Hiroji Iwata ${ }^{3)}$, Hiroko Bando ${ }^{4)}$, Tetsuji Ohyama ${ }^{5)}$, Naoto Kondo ${ }^{3)}$, Kentaro Nakajima ${ }^{1)}$,Takahiro Hiratsuka ${ }^{1)}$, Masafumi Inomata ${ }^{1)}$, Seigo Kitano6)

1 ) Department of Gastroenterological and Pediatric Surgery, Oita University Faculty of Medicine 2 ) Breast Oncology Center, The Cancer Institute Hospital 3 ) Department of Breast Oncology, Aichi Cancer Center 4 ) Department of Breast and Endocrine Surgery, Faculty of Medicine, University of Tsukuba 5 ) Department of Clinical Statistics and Data Management, Oita University Faculty of Medicine, 6 ) Oita University

\section{Objective}

Chemotherapy-induced alopecia $(\mathrm{ClA})$ is one of the most distressing and unavoidable adverse events of chemotherapy in breast cancer patients. According to a questionnaire-based research in a population of Japanese patients who had received chemotherapy for breast cancer, the hair recovery rate in approximately $10 \%$ of patients was less than $50 \%$ after completing $1-$ 2 years of chemotherapy. There is no drug to prevent CIA. The application of DHL-HisZnNa(Fig.1), an $\alpha$-lipoic acid derivative, had a preventive effect on CIA in rodent models. ${ }^{1)}$ Therefore, we performed a multicenter clinical trial to assess whether the application of DHL-HisZnNa reduces CIA in breast cancer patients.

\section{Methods}

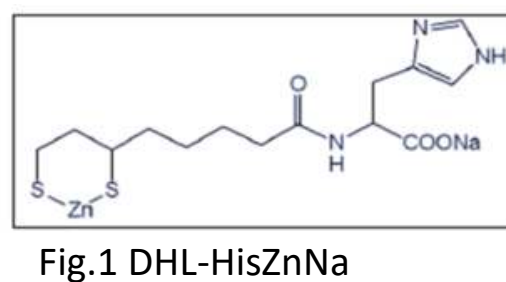
chemical structural formula Trial design The clinical trial was a multicenter, single-arm study (Fig.2) on women planning to receive adjuvant chemotherapy.(Table1)

Number of patients 100 patients

$$
\text { (P) } \Rightarrow \text { Intervention }
$$
Follow-up period: 1 year after chemotherapy completion Fig.2 Study design Inclusion criteria: pathological diagnosis of breast cancer

treatment plan including anthracycline and/or taxane chemotherapy 20-80 year-old patient

Performance Status(PS) : 0 1

Exclusion criteria:

previous history of severe drug hypersensitivity

chemotherapy contraindication

previous history of cosmetics or hair growth agent hypersensitivity severe complication pregnancy or lactation

Table1.Inclusion/exclusion criteria

End points The primary end point was the proportion of participants with grade 2 alopecia ( $\geqq 50 \%$ hair loss, Common Terminology Criteria for Adverse Events version 4.0)(Table2).

The secondary end points were adverse events related to the study drug and symptoms associated with hair loss.

$\begin{array}{ll}\text { Alopecia } & \\ \text { grade } 0 & \text { no hair loss } \\ \text { grade } 1 & \begin{array}{l}\text { hair loss of }< \\ 50 \% \text { of normal }\end{array} \\ \text { grade 2 } & \begin{array}{l}\text { hair loss of } \geqq \\ 50 \% \text { of normal }\end{array} \\ & \begin{array}{l}\text { Table2 alopecia grade } \\ \text { (CTCAE ver.4.0) }\end{array}\end{array}$

Procedure During chemotherapy, $4 \mathrm{ml}$ of a topical product containing $1 \% \mathrm{DHL}$ HisZnNa was applied to the scalp four times a day.(Fig.2)

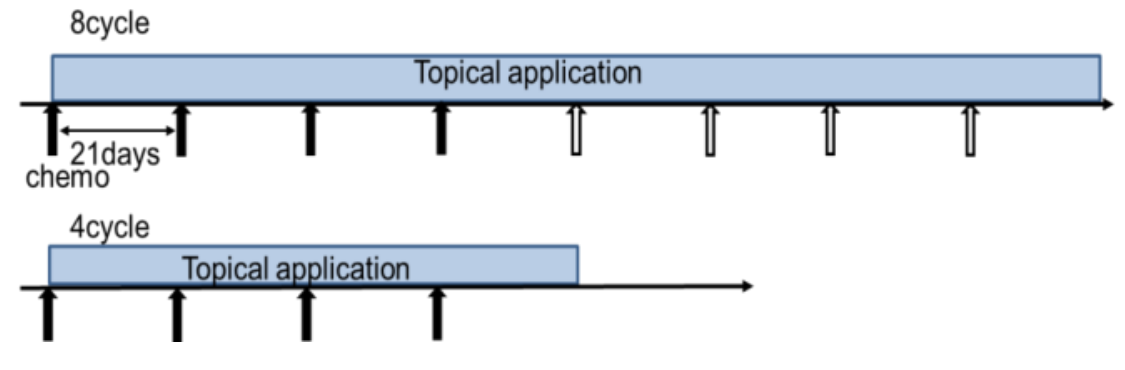

Fig.3 Intervention schedule

Evaluation methods The way to evaluate the alopecia grade is that 3 commissioners determine respectively the grade from 4-way photographs(Fig.3) of participant's head.

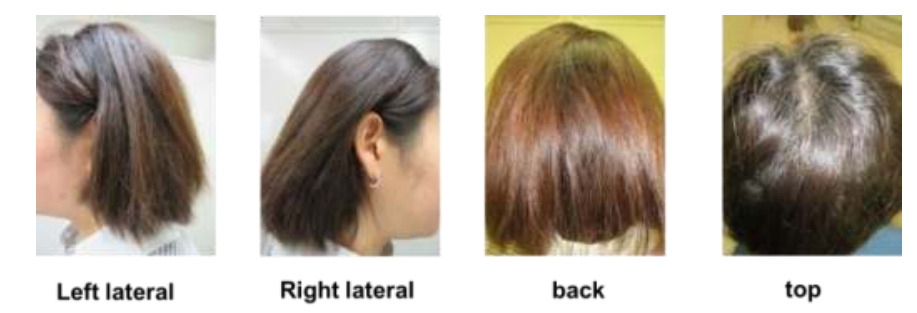

\section{Results}

Fig.4 Patient's head photograph

\section{Patients characteristics}

101 participants were enrolled from July 2014 to May 2015. The mean age was 50 years old; $34 \%$ of participants $(n=34)$ received 4 cycles of chemotherapy, and $66 \%(n=67)$ received 8 cycles of chemotherapy. (Table2)

\begin{tabular}{|c|c|c|}
\hline Age,y & median(range) & $50(22-75)$ \\
\hline \multirow[t]{2}{*}{ Menstrual status,No. } & premenopause & 61 \\
\hline & postmenopause & 40 \\
\hline \multirow[t]{2}{*}{ PS,No. } & & 99 \\
\hline & & 2 \\
\hline \multirow[t]{7}{*}{ Breast cancer stage, No. } & I & 35 \\
\hline & II A & 32 \\
\hline & II B & 17 \\
\hline & IIIA & 9 \\
\hline & III B & 5 \\
\hline & IIIC & 2 \\
\hline & IV & 1 \\
\hline \multicolumn{3}{|l|}{ pretreatment,No.(\%) } \\
\hline \multirow[t]{2}{*}{ operation } & no & $32(32)$ \\
\hline & yes & $69(68)$ \\
\hline \multirow[t]{3}{*}{ radiation (for breast) } & no & 100(99) \\
\hline & yes & 0 \\
\hline & unnown & 1(1) \\
\hline \multirow[t]{3}{*}{ hormone } & no & 98(97) \\
\hline & yes & $2(2)$ \\
\hline & unkown & $1(1)$ \\
\hline \multirow[t]{3}{*}{ chemotherapy } & no & 100(99) \\
\hline & yes & 0 \\
\hline & unknouwn & $1(1)$ \\
\hline \multirow[t]{3}{*}{ Trastuzumab } & no & 99(98) \\
\hline & yes & $1(1)$ \\
\hline & unknown & $1(1)$ \\
\hline
\end{tabular}

Table3. Patients charactaristics

Efficacy The rate of grade 2 alopecia was 100\% (101/101), Grade 2 alopecia was occurred in all pts (101/101), but the recovered rate to less than G1 were $93 \%(94 / 101)$ and $100 \%$ at three and six months after the completion of chemotherapy, respectively.(Fig.5)

4 cycles chemotherapy $(n=34)$ 8 cycles chemotherapy $(n=67)$
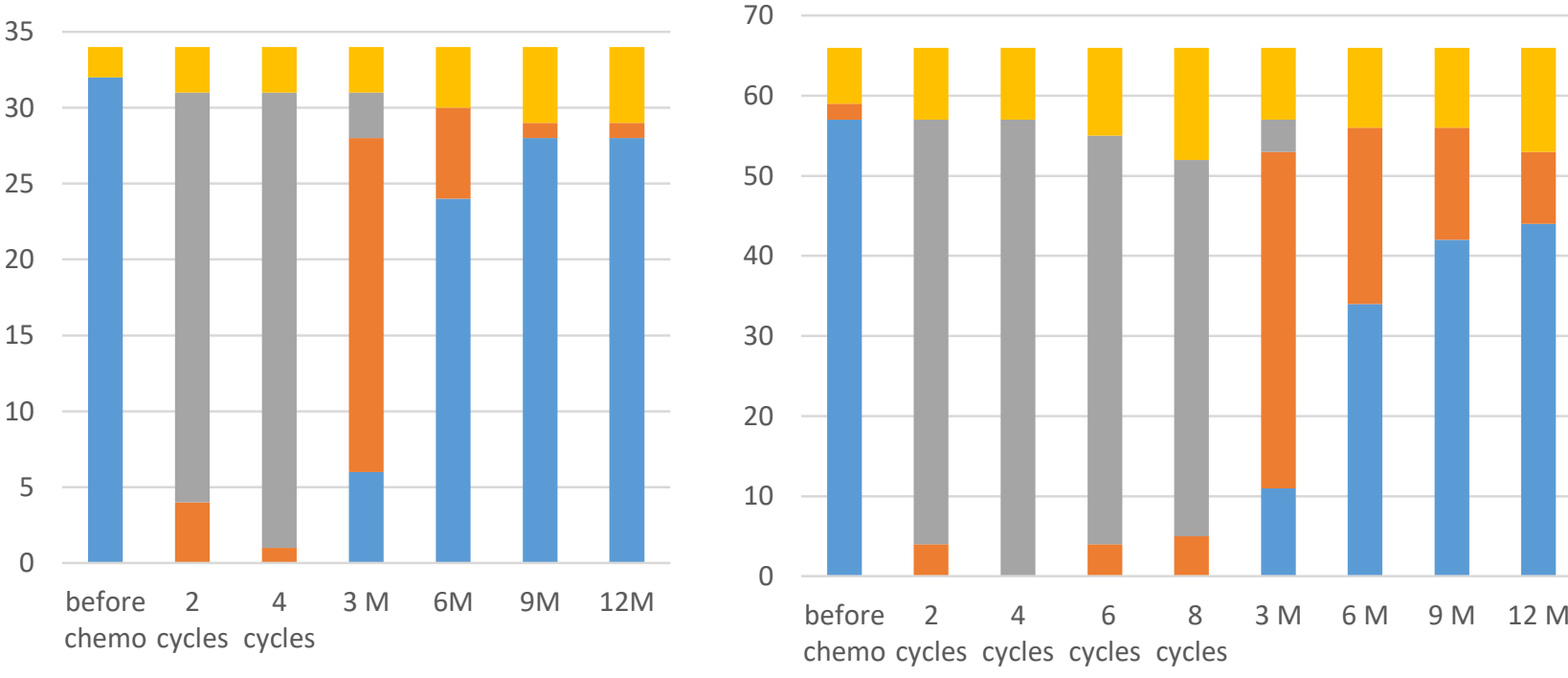

$\square$ Grade0 $\square$ Grade1 $\square$ Grade2 $\square$ unknown

Fig.5 Alopecia grade change

Safety

All adverse events ( $n=11,11 \%$ ) were grade 1 or grade 2 , and these included scalp pain $(n=3)$, pruritus $(n=3)$, and rash $(n=5)$.

Symptoms associated with hair loss were found in 53 patients (52\%), including scalp pain in 25 patients and scalp itching in 35 patients.

\section{Discussion}

There is no complete prevention of $\mathrm{CIA}$ at present. There is no evidence about alopecia grade change after chemotherapy, but $41 \%$ of patients who had chemotherapy reported their hair regrowth occurred 6 weeks after chemotherapy. ${ }^{2)}$ In our study, the rate of alopecia grade 1 or 03 months after chemotherapy is $81 \%(71 / 88)$.

We didn't set the control group and our endpoints are different, so we couldn't reach the conclusion, but application of $\alpha$-lipoic acid might promote hair regrowth.

\section{Conclusion}

The results in our study suggested DHL-HisZnNa showed no preventive effect, but promoted the function of hair growth in $\mathrm{CIA}$ patients. We have a new study plan to confirm the interesting function of this application.

\section{Reference}

1) Surg Today. 2011 May;41(5):693-7

2) Eur J Oncol Nurs. 2013 Oct;17(5):536-40

COI: This study was funded by Aderans Co.,Ltd. 